\title{
Expeditious procedures to support the educational process in Combat Sports - an exploratory study
}

Helder LOPES ${ }^{* 1,3}$, Catarina FERNAND01,3, João PRUDENTE1,3, Joana SIMÕES1 ${ }^{1}$, Miguel VIEIRA1 , \& António VICENTE2,3

${ }^{1}$ Department of Physical Education and Sports - University of Madeira (Portugal)

2 Department of Physical Education and Sports - University of Beira Interior (Portugal)

${ }^{3}$ Research Centre for Health, Sport and Human Development (CIDESD) (Portugal)

\section{Introduction}

Combat Sports can be a powerful tool to transform individuals. They are a privileged device to induce behaviors that requires the individual to constantly read the opponent and make decisions in critical situations by assuming the possibility of symbolic death (by ippon or knock-out), a structural role in the actions of every individual (Almada, Fernando, Lopes, Vicente \& Victoria, 2008). However, in order to intervene in a profitable way it is necessary to personalize the processes according to the capacities and abilities of the individual.

To individualize, a good diagnosis is decisive for a proper prescription and an effective control of the entire process. However, in addition to the necessary development of diagnostic and control tools increasingly precise using the nowadays available laboratory facilities, we must explore and operationalize expeditious processes of diagnosis and control because we cannot get into processes with costs that are unaffordable or difficult to operationalize in a training context. Contrary to what is often thought laboratory support does not have to be about large costs or expensive equipment if we use expeditious procedures (Lopes, Fernando, Vicente, Simões \& Prudente, 2012). To compensate for the natural loss of precision in the short term, evolutionary trends need to be used to understand the phenomena and intervene.

So that things do not happen by mere reproduction of standardized processes, the diagnosis in ecological context (that enables to cross data) is strategic.

\section{Methodology}

In order to operationalize the diagnosis, through expeditious procedures and regarding the ability to adapt to different contexts according to timely appropriate strategies, we've developed an exploratory study with 22 university students ( 4 females and 18 males) aged 19 to 35 years (mean age: $21.3 \pm 3.7$ years). Two experimental situations were held in class context. 1st situation: in the first 10 minutes of 5 classes we've used team games situations with different targets and scoring systems with different levels of difficulty and risk, where the rules were changed throughout the game. 2nd situation: in the next 10 minutes of each class student performed combat situations where the goal varied (put out of the mat 5 times, touch as many times as possible on one of the opponent's foot for one minute, then the same two situations but with the notion of symbolic death, that is to put off the mat once and hit the foot once).

Students were assessed in each situation depending on the ability to timely adapt to the change of rules, depending on the outcome and the available time. We've considered three performance 
levels: 1 - did not change their behavior; 2 - behavior changed from time to time; and 3 - behavior changed most of the times - more than 50\%. A note card specifically built for this purpose was used to collect data. Direct observations were performed by two observers (participants in situations) being considered only the results where there was agreement between both.

\section{Results}

We've found that in the 1st situation $22.7 \%$ (5) of the students did not change their behavior, $40.9 \%$ (7) punctually changed it and $36.4 \%$ (8) changed it most of the times (over 50\%).

In the 2 nd situation only $13.4 \%$ (3) of the students changed their level of performance in relation to the 1st situation. There were 3 students who had been categorized as having changed their behavior more often in the 1st situation (team sports) who went to the category of occasionally altered their behavior in the 2nd situation (combat sports). $86.4 \%$ of the students had their behavior characterized in the same way in both situations.

\section{Discussion and conclusion}

When we get such a high percentage (86.4\%) of maintenance of the same type of behavior between two types of situations with different goals and most striking features (Almada, et al., 2008; Vieira, Fernando, Apolinário, \& Lopes, 2014) it seems to us to be sufficient evidence to follow this line of research. That is, the use of non-intrusive expeditious processes, in ecological context, to support the educational process appears to be feasible and can be an asset in the characterization of variables that are usually assessed through laboratory processes conducted by external elements to the educational process (e.g. psychologists). The future aim is to make it possible to identify and characterize evolutionary trends associated with the capabilities and potential of each individual and not only to identify specific behaviors that may be triggered by very specific stimuli.

\section{References}

Almada, F., Fernando, C., Lopes, H., Vicente, A., \& Vitória, M. (2008). A Rotura - A Sistemática das Actividades Desportivas. Torres Novas: Edição VML.

Lopes, H., Fernando, C., Vicente, A., Simões, J., \& Prudente, J. (2012). O Processo Pedagógico - formas expeditas de apoio laboratorial. In SCPD (Org.). Desporto e Pedagogia, Formação e investigação (pp. 83-92). Lisboa: Edição Coisas de Ler.

Vieira, M., Fernando, C., Apolinário, J., \& Lopes, H. (2014). Os Desportos de Combate Enquanto Meio de Transformação do Homem. Revista da Sociedade Científica de Pedagogia do Desporto, 1(5), 4348.

Key words: Pedagogical process; diagnosis; expeditious procedures; combat sports. 